\title{
Declines in health literacy and health- related quality of life during the COVID-19 pandemic: a longitudinal study of the Japanese general population
}

Hirono Ishikawa ${ }^{1 *}$, Mio Kato ${ }^{1}$ and Takahiro Kiuchi ${ }^{2}$

\begin{abstract}
Background: During the coronavirus disease 2019 (COVID-19) pandemic, the importance of health literacy (HL) was addressed by public health researchers. We longitudinally examined the changes in general $\mathrm{HL}$ and health-related quality of life (HRQOL) between immediately before the COVID-19 outbreak and 1 year later, and how general HL before the outbreak was related to changes in HRQOL in the Japanese general population.

Methods: Among the Japanese residents aged 20-79years who participated in our previous study in 2017, 826 were followed-up via self-administered questionnaires in January 2020 and February 2021, for the purposes of this study. The HRQOL was measured using the SF-8, a short version of the SF-36 Health Survey, and general HL was measured using the short form of the European Health Literacy Survey Questionnaire (HL-SF12) in the 2020 and 2021 surveys.

Results: The physical and mental dimensions of HRQOL as well as general HL declined significantly from immediately before the COVID-19 outbreak to 1 year later $(p=.010, p<.001$ and $p<.001$, respectively). The decline in HRQOL, especially the mental dimension, was more significant among women. A lower economic status was also related to a greater decline in HRQOL ( $p=.026$ for the physical dimension and $p=.012$ for the mental dimension). Higher general HL before the COVID-19 outbreak was associated with a lesser decline in HRQOL in both the physical and mental dimensions ( $p=.040$ and $p<.001$, respectively) after controlling for possible confounding variables such as gender and economic status.

Conclusions: Healthcare support is crucial for vulnerable populations during and after the pandemic. General $\mathrm{HL}$ may be important for attenuating the decline in $\mathrm{HRQOL}$, by enabling effective use of health information and adaptive behaviors toward health threats. Further studies are needed to better understand the association between $\mathrm{HL}$ and HRQOL.
\end{abstract}

Keywords: COVID-19, Health literacy, Health related quality of life, Longitudinal study

\footnotetext{
* Correspondence: hirono-tky@umin.ac.jp

${ }^{1}$ Graduate School of Public Health, Teikyo University, 2-11-1 Kaga, Itabashi-ku, Tokyo 173-8605, Japan

Full list of author information is available at the end of the article
}

(c) The Author(s). 2021 Open Access This article is licensed under a Creative Commons Attribution 4.0 International License, which permits use, sharing, adaptation, distribution and reproduction in any medium or format, as long as you give appropriate credit to the original author(s) and the source, provide a link to the Creative Commons licence, and indicate if changes were made. The images or other third party material in this article are included in the article's Creative Commons licence, unless indicated otherwise in a credit line to the material. If material is not included in the article's Creative Commons licence and your intended use is not permitted by statutory regulation or exceeds the permitted use, you will need to obtain permission directly from the copyright holder. To view a copy of this licence, visit http://creativecommons.org/licenses/by/4.0/. The Creative Commons Public Domain Dedication waiver (http://creativecommons.org/publicdomain/zero/1.0/) applies to the data made available in this article, unless otherwise stated in a credit line to the data. 


\section{Background}

Since the outbreak of coronavirus disease 2019 (COVID19), many countries have experienced large-scale societal changes that have had a profound impact on everyday life and behaviors. Governments have introduced substantial restrictions on people's movements, including stay-at-home orders, limitations on gatherings, and the closure of non-essential workplaces. Although this was crucial for preventing the spread of COVID-19, such restrictions have led to severe economic downturns and job insecurity [1], which in turn had negative impacts on health and health-related behaviors.

Several large studies in the US and Europe reported a deterioration in mental health and health behaviors between the time before and during the COVID-19 pandemic [2-8]. Although the declines were observed across sociodemographic groups, some groups exhibited a greater decline in health, such as the young and women $[2,5,7]$. Also, declines in health-related quality of life (HRQOL) from before to during the pandemic have been reported among adolescents [9] and cancer patients [10]. In Japan, the prevalence of depressive symptoms increased among older adults [11], and physical activity decreased in the general adult population $[12,13]$. A reduced level of physical activity is associated with depression and anxiety [14]. Therefore, COVID-19 not only directly affected health but also indirectly impacted HRQOL by mandating changes in social norms and daily life.

During the COVID-19 pandemic, the importance of health literacy (HL) was addressed by public health researchers [15-22]. HL is defined as "people's knowledge, motivation and competences to access, understand, appraise, and apply health information in order to make judgments and take decisions in everyday life concerning healthcare, disease prevention and health promotion to maintain or improve quality of life during the life course [23]." Research concerning HL in the context of the COVID-19 pandemic is nascent, so there is insufficient information on the relationships of HL with health behaviors and outcomes [24]. However, several crosssectional studies have reported that lower HL is associated with confusion regarding COVID-19 [25] and erroneous beliefs [26-28]. Moreover, and protective behaviors are less frequently adopted in those with lower HL $[27,28]$. In a Japanese study, higher HL was associated with exercise during the COVID-19 state of emergency [29]. Furthermore, studies of healthcare workers have reported that higher HL protects against mental health problems and is associated with higher HRQOL [30, 31]. Additionally, a cross-sectional study of outpatients reported that higher HL was associated with a lower likelihood of depression and higher HRQOL [32], which moderated the negative impact of fear of COVID-
19 on HRQOL [33]. However, no longitudinal study has examined the association of general HL before the COVID-19 pandemic with changes in health status during the pandemic among the general public.

In this study, we longitudinally examined the changes in HRQOL and general HL between 2020 (immediately before the COVID-19 outbreak) and 2021 (1 year later) and how general HL before the outbreak was related to changes in HRQOL in the Japanese general population.

\section{Methods \\ Participants}

Figure 1 shows the timeline of the surveys and the sample of this study. Participants were originally recruited for a survey in 2017 from a pool of Japanese residents obtained from a survey research company database. The survey was designed to investigate HL among the Japanese general population and its relationship with healthrelated behaviors [34, 35]. During the survey, we collected data from 1002 men and women aged 20-79 years. Respondents who met the inclusion criteria were randomly invited to participate by fax/mail. When enrolling participants from the database, we attempted to match them in terms of gender and age distributions with data from the 2016 national census of the Japanese population. Responses were obtained from potential participants until the target numbers for each gender and age group were met. Individuals who agreed to participate were asked to provide a completed consent form. A set of self-administered questionnaires was mailed to the participants. For the purpose of this study, the participants of the 2017 survey $(N=1002)$ were followed up using surveys in early January $2020(N=876)$ and again in February $2021(N=826)$. The first case of COVID-19 in Japan was confirmed on January 16, 2020. For this study, we used the data of 826 individuals who participated in both the 2020 and 2021 surveys. The response rate for the 2020 survey was $87.4 \%$ (876 of 1002), and that for the 2021 survey was $94.3 \%$ ( 826 of 876 ).

\section{Measures \\ Health-related quality of life}

The SF-8, a short version of the SF-36 Health Survey, was used to measure HRQOL in the 2020 and 2021 surveys [36]. The SF-8 consists of eight items assessing general health, physical functioning, role limitations due to physical functioning, bodily pain, vitality, social functioning, mental health, and role limitations due to emotional functioning. Two summary scores, the physical component summary (PCS) and mental component summary (MCS) scores, are calculated as the weighted sum of each item's score, transformed into T-scores, and normalized to the Japanese general population (50 points represents the national average value). The PCS and 
2017 survey (for previous studies [34, 35])

Conducted in February, 2017

$\mathrm{N}=1002$, recruited form the research company database

\section{Sample of this study}

2020 survey

Conducted in January, 2020

$\mathrm{N}=876$

Assessed HRQOL, HL, and

sociodemographic variables

Conducted in February, 2021

$\mathrm{N}=826$

Assessed HRQOL, HL, and

sociodemographic variables

Fig. 1 Timeline of the surveys and the sample of this study

MCS scores indicate physical and mental functioning, respectively, with higher scores indicating a higher HRQOL.

\section{Health literacy}

The short form of the European Health Literacy Survey Questionnaire (HL-SF12) was used in this study. The original European Health Literacy Survey Questionnaire (HLS-EU-Q47) was developed to measure HL in the general population [37] based on a conceptual framework reflecting four information-processing dimensions (i.e., accessing, understanding, appraising, and applying) within three health domains (i.e., health care, disease prevention, and health promotion) [23], and has been validated in a Japanese population [38]. The HL-SF12 consists of 12 items selected from each domain of the HLS-EU-Q47 and has been validated in an Asian general population [39]. Each item assesses the perceived difficulty of completing a specific health-related task, rated on a four-point Likert scale $(1=$ very difficult, 2 =difficult, 3 = easy, and 4 = very easy) with a "don't know" option. Responses of "don't know" were treated as missing and not included in the calculations of the participants' index scores [38]. Using the scores of all 12 items, we constructed a comprehensive general index for HL. Following the original study, a mean-based item raw score was computed for respondents who provided valid responses to at least $80 \%$ of the HL questions [40]. The index score was standardized to unified metrics from 0 to 50 using the following formula: (mean - 1) $\times(50 / 3)$. Cronbach's alpha for the scale was 0.891 in 2020 and 0.889 in 2021.

\section{Sociodemographic data}

The following demographic data were obtained as part of both 2020 and 2021 survey: age (years), gender (male or female), educational attainment (junior high school, high school/vocational school, 2-year college, university or higher), self-assessed economic status (rated on a 10point scale ranging from $1=$ lowest to $10=$ highest in society), work status (self-employed, full-time employed, part-time employed, and others [including retirees, homemakers, students, and individuals not in a paid job for any reason]), and the presence of a currently treated 
disease (i.e. whether participants had a disease being treated during the previous year [yes or no]).

\section{Statistical analysis}

The changes in HRQOL and HL between 2020 and 2021 were examined using paired $t$-tests. The changes in HRQOL were calculated by subtracting the HRQOL scores of 2021 from those of 2020. Multiple linear regression analysis controlling for sociodemographic variables and HRQOL in 2020 was performed to examine the relationship between HL in 2020 and changes in HRQOL. The sociodemographic data obtained from the 2021 survey were used because these data were considered to reflect the situation during the first year of the pandemic. In addition to age, gender, and educational attainment, which were typically adjusted for in previous HL studies, other sociodemographic variables correlated with HRQOL or HL in the bivariate analysis $(p<.20)$ were included in the regression models. Stratified analyses by gender were also performed. Missing data were deleted list-wise. Data were analyzed using Stata ver. 16.1 (StataCorp, College Station, TX).

\section{Results}

\section{Participants' characteristics and descriptive statistics}

Table 1 summarizes the sociodemographic characteristics of the participants in the 2020 and 2021 surveys. In the 2021 survey, the mean age was 54.6 years (standard deviation $[\mathrm{SD}]=16.0$ years), and $48.6 \%$ were males. Of the 826 participants, $40.3 \%$ had graduated from university, and $47.1 \%$ were full-time workers, including selfemployed and full-time employed workers. There were 358 individuals (43.3\%) who had a disease for which they had received treatment during the past year.

\section{Changes in HRQOL and HL between 2020 and 2021}

There were significant declines in both dimensions of HRQOL (PCS and MCS) and HL between 2020 and 2021 (Table 2). The mean HL score was $30.5(\mathrm{SD}=8.8)$ in 2020, which declined to $28.7(\mathrm{SD}=8.8)$ in 2021. Although there are no normative data for this scale in the general Japanese population, the mean score for our 2017 survey using the 47 -item version of the scale was $29.79(\mathrm{SD}=7.41)$ [34], which was somewhat higher than the $25.3(\mathrm{SD}=8.2)$ reported in a previous online survey study on the general Japanese population using the same scale [38], but still lower than the value of 33.78 ( $\mathrm{SD}=$ 7.95) reported by a previous European study [40].

When stratified by gender, the declines in the PCS and MCS scores were statistically significant only among females. By contrast, HL declined significantly for both men and women.
Factors related to the decline in HRQOL

As shown in Table 3, those with higher HL in 2020 had a significantly smaller decline in score for the physical dimension of HRQOL (PCS) than those with lower HL. A lower economic status and the presence of a disease under treatment were associated with a greater decline. When stratified by gender, HL in 2020 had a significant association with the PCS score only among women.

Similarly, HL in 2020 was significantly associated with a decline in the score for the mental dimension of HRQOL (MCS) (Table 4). The decline was greater for women, those of lower economic status, and those with a disease under treatment. When stratified by gender, the relationship between HL in 2020 and a decline in MCS score was more evident among men, and working full-time was related to a greater decline in the MCS score among women.

\section{Discussion}

This study longitudinally examined the changes in HRQOL and general HL between immediately before the COVID-19 outbreak and 1 year later, and how HL before the outbreak was related to changes in HRQOL in the Japanese general population.

Overall, scores for the physical and mental dimensions of HRQOL declined significantly from immediately before the COVID-19 outbreak to 1 year later. The findings are generally consistent with previous studies in Western countries that reported deterioration in mental health and well-being $[2,4-7]$. A previous study also reported that loneliness was associated with a higher incidence of suicidal ideation during the COVID-19 pandemic [41]. In Japan, unlike some US states and European countries, strong legal restrictions such as a complete "lockdown" have not been enacted thus far. Instead, the government repeatedly declared a state of emergency and imposed a voluntary stay-at-home order, except for essential tasks. Nevertheless, previous studies on the Japanese population have reported increased mental health problems $[11,42]$ and decreased physical activity and perceived physical fitness $[12,13]$. Our findings are in line with these reports.

Further, the decline in HRQOL, especially the mental dimension, was more significant among women, consistent with previous reports $[2,5,7]$. Women may experience a disproportional burden of the economic shock associated with COVID-19, greater increases in childcare responsibilities and interruptions to paid work, and more job loss [5]. Although the COVID-19 pandemic's effects on employment have been less severe in Japan compared to Western countries, the employment of non-regular employees and young people has declined [43]. Female employment is suggested to be affected more than male employment, because women make up a large 
Table 1 The characteristics of the study participants

\begin{tabular}{|c|c|c|c|c|}
\hline & \multicolumn{2}{|c|}{2020} & \multicolumn{2}{|c|}{2021} \\
\hline & $\bar{N}$ & $\%$ & $\bar{N}$ & $\%$ \\
\hline \multicolumn{5}{|l|}{ Age } \\
\hline $20-29$ & 80 & 9.7 & 67 & 8.1 \\
\hline $30-39$ & 110 & 13.3 & 109 & 13.2 \\
\hline $40-49$ & 140 & 17.0 & 126 & 15.3 \\
\hline $50-59$ & 178 & 21.6 & 187 & 22.6 \\
\hline $60-69$ & 151 & 18.3 & 146 & 17.7 \\
\hline 70- & 167 & 20.2 & 191 & 23.1 \\
\hline Mean (SD) & 53.4 & 16.0 & 54.6 & 16.0 \\
\hline \multicolumn{5}{|l|}{ Gender } \\
\hline Male & 401 & 48.6 & 401 & 48.6 \\
\hline Female & 425 & 51.5 & 425 & 51.5 \\
\hline \multicolumn{5}{|l|}{ Educational attainment } \\
\hline Junior high school & 30 & 3.6 & 30 & 3.6 \\
\hline High school/Nocational school & 348 & 42.1 & 348 & 42.1 \\
\hline 2-year college & 115 & 13.9 & 115 & 13.9 \\
\hline University or higher & 333 & 40.3 & 333 & 40.3 \\
\hline \multicolumn{5}{|l|}{ Self-assessed economic status } \\
\hline Low:1-3 & 139 & 16.8 & 139 & 16.8 \\
\hline Middle low: 4-5 & 354 & 42.9 & 337 & 40.8 \\
\hline Middle high: 6-7 & 292 & 35.4 & 301 & 36.4 \\
\hline High: 8-10 & 39 & 4.7 & 45 & 5.5 \\
\hline missing & 2 & 0.2 & 4 & 0.5 \\
\hline \multicolumn{5}{|l|}{ Work status } \\
\hline Self-employed & 78 & 9.4 & 84 & 10.2 \\
\hline Full-time employed & 320 & 38.7 & 305 & 36.9 \\
\hline Part-time employed & 148 & 17.9 & 154 & 18.6 \\
\hline Others & 278 & 33.7 & 281 & 34.1 \\
\hline missing & 2 & 0.2 & 2 & 0.2 \\
\hline \multicolumn{5}{|c|}{ Presence of a currently treated disease } \\
\hline Yes & 358 & 43.3 & 358 & 43.3 \\
\hline No & 442 & 53.5 & 456 & 55.2 \\
\hline missing & 26 & 3.2 & 12 & 1.5 \\
\hline
\end{tabular}

proportion of employment in industries involving interpersonal services, such as the food service and accommodation sectors, and many of those are engaged in non-regular employment [44]. In addition, among women, working full-time was associated with a greater decline in the score for the mental dimension of HRQOL. This may reflect difficulties in balancing work and family resulting from school closures and remote work during the pandemic. Mental health support for vulnerable populations such as women and those with a lower economic status is thus crucial during and after the pandemic.
Notably, the decline in HRQOL was greater in those with a disease currently being treated, possibly due to the challenges associated with managing a chronic condition during the pandemic. People with certain underlying medical conditions are at increased risk of serious illness from COVID-19. Previous studies reported that patients with chronic diseases reduced their number of medical visits during the pandemic, partly because of the fear of getting infected with COVID-19 at medical institutions $[45,46]$. To reduce the increase in non-COVID19-related morbidity and mortality, it is critical to encourage patients with chronic diseases to continue to 
Table 2 Changes in HRQOL and HL between 2020 and 2021

\begin{tabular}{|c|c|c|c|c|c|c|c|c|}
\hline & & 2020 & & 2021 & & Chang & 020 & \\
\hline & $\mathbf{N}$ & Mean & $\overline{S D}$ & Mean & $\overline{S D}$ & Mean & SD & $p$-value ${ }^{1)}$ \\
\hline HRQOL-physical & 817 & 44.83 & 7.13 & 44.15 & 7.38 & -0.68 & 7.58 & 0.010 \\
\hline male & 399 & 45.18 & 6.75 & 44.62 & 6.89 & -0.56 & 6.94 & 0.107 \\
\hline female & 418 & 44.50 & 7.48 & 43.70 & 7.80 & -0.80 & 8.15 & 0.045 \\
\hline HRQOL-mental & 817 & 49.72 & 7.14 & 48.63 & 7.84 & -1.09 & 7.49 & $<.001$ \\
\hline male & 399 & 49.82 & 7.08 & 49.33 & 7.53 & -0.48 & 7.06 & 0.172 \\
\hline female & 418 & 49.62 & 7.21 & 47.96 & 8.08 & -1.66 & 7.84 & $<.001$ \\
\hline Health literacy & 730 & 30.53 & 8.80 & 28.75 & 8.82 & -1.78 & 6.62 & $<.001$ \\
\hline male & 351 & 29.85 & 9.08 & 28.03 & 9.09 & -1.83 & 6.71 & $<.001$ \\
\hline female & 379 & 31.16 & 8.49 & 29.41 & 8.52 & -1.74 & 6.55 & $<.001$ \\
\hline
\end{tabular}

1) Paired t-test for changes between 2020 and 2021

receive care, and to develop healthcare services to support them, including those delivered by telephone or online.

General HL also declined significantly. HL is mediated by organizational structures and the availability of resources that enable people to access, understand, appraise, and use information and services in ways that promote and maintain good health for themselves and those around them [47]. In particular, the measure of HL used in this study is designed to measure the subjective manageability of health-related tasks, focusing on both individuals and underlying circumstances in which health-related tasks are performed [40, 48]. The lower score in 2021 may reflect difficulties in obtaining and understanding adequate information in the context of COVID-19, where many problems in health communication has emerged. During the pandemic, false or contradictory information spread rapidly via social media and other Internet outlets, and the "infodemic" (the global epidemic of misinformation) has posed a serious problem for public health [49]. Although governments and health authorities have provided information on the risk of COVID-19 and how to prevent contracting or spreading the infection, there has been concern that educational materials and websites on COVID-19 provide information at a readability level far exceeding that recommended for patient information [50,51].

Higher general HL before the COVID-19 outbreak was associated with less decline in HRQOL. This is consistent with previous cross-sectional studies suggesting that higher HL was associated with a lower likelihood of mental problems and higher HRQOL [30-32]. As discussed above, HL is considered to play an important role in the acquisition, understanding, and use of information, which might have prompted the adoption of adaptive behaviors toward health threats [25-28], and moderated the negative impact of fear of COVID-19 on HRQOL [33]. In addition, as to the physical dimension, those with higher HL might have engaged in more health-promoting activities during the pandemic to

Table 3 Factors related to the decline in HRQOL-physical by gender

\begin{tabular}{|c|c|c|c|c|c|c|}
\hline & \multicolumn{2}{|c|}{ Total $(N=749)$} & \multicolumn{2}{|c|}{ Male $(N=363)$} & \multicolumn{2}{|c|}{ Female $(N=386)$} \\
\hline & B & $95 \% \mathrm{Cl}$ & B & $95 \% \mathrm{Cl}$ & B & $95 \% \mathrm{Cl}$ \\
\hline Age & 0.006 & $(-0.029$ to 0.042$)$ & 0.032 & $(-0.016$ to 0.079$)$ & -0.024 & $(-0.078$ to 0.030$)$ \\
\hline Gender & -0.392 & $(-1.466$ to 0.683$)$ & & & & \\
\hline Education & -0.109 & $(-0.607$ to 0.389$)$ & 0.084 & $(-0.533$ to 0.700$)$ & -0.457 & $(-1.282$ to 0.368$)$ \\
\hline Economic status & 0.358 & $(0.043$ to 0.672$)$ & 0.164 & $(-0.245$ to 0.573$)$ & 0.527 & (0.045 to 1.010$)$ \\
\hline Having a disease & -1.602 & $(-2.685$ to -0.520$)$ & 0.183 & $(-3.234$ to -0.372$)$ & -1.297 & $(-2.932$ to 0.338$)$ \\
\hline Full-time worker & 1.053 & $(-0.102$ to 2.209$)$ & 1.665 & (0.124 to 3.206$)$ & 0.319 & $(-1.436$ to 2.075$)$ \\
\hline HRQOL-physical at 2020 & -0.594 & $(-0.663$ to -0.524$)$ & 0.564 & $(-0.661$ to -0.466$)$ & -0.616 & $(-0.716$ to -0.515$)$ \\
\hline $\mathrm{HL}$ at 2020 & 0.057 & $(0.003$ to 0.112$)$ & 0.028 & $(-0.042$ to 0.098$)$ & 0.092 & $(0.007$ to 0.177$)$ \\
\hline (constant) & 23.327 & (18.448 to 28.205$)$ & 21.102 & (15.231 to 26.972$)$ & 24.155 & (17.707 to 30.603 ) \\
\hline Adjusted R-squared & 0.270 & & 0.259 & & 0.278 & \\
\hline
\end{tabular}

Multiple linear regression analysis was used. Significant differences are printed in bold $(p<0.05)$ 
Table 4 Factors related to the decline in HRQOL-mental by gender

\begin{tabular}{|c|c|c|c|c|c|c|}
\hline & \multicolumn{2}{|c|}{ Total $(N=749)$} & \multicolumn{2}{|c|}{ Male $(N=363)$} & \multicolumn{2}{|c|}{ Female $(N=386)$} \\
\hline & B & $95 \% \mathrm{Cl}$ & B & $95 \% \mathrm{Cl}$ & B & $95 \% \mathrm{Cl}$ \\
\hline Age & 0.019 & $(-0.018$ to 0.056$)$ & 0.017 & $(-0.033$ to 0.067$)$ & 0.027 & $(-0.028$ to 0.081$)$ \\
\hline Gender & -2.046 & $(-3.145$ to -0.947$)$ & & & & \\
\hline Education & -0.246 & $(-0.756$ to 0.263$)$ & -0.535 & $(-1.179$ to 0.108$)$ & 0.136 & $(-0.692$ to 0.965$)$ \\
\hline Economic status & 0.416 & (0.093 to 0.738$)$ & 0.409 & $(-0.019$ to 0.837$)$ & 0.377 & $(-0.111$ to 0.865$)$ \\
\hline Having a disease & -1.123 & $(-2.204$ to -0.042$)$ & -0.786 & $(-2.258$ to 0.686$)$ & -1.375 & $(-2.965$ to 0.215$)$ \\
\hline Full-time worker & -0.916 & $(-2.099$ to 0.267$)$ & 0.310 & $(-1.294$ to 1.914$)$ & -2.014 & $(-3.783$ to -0.246$)$ \\
\hline HRQOL-mental at 2020 & -0.502 & $(-0.573$ to -0.431$)$ & -0.486 & $(-0.583$ to -0.388$)$ & -0.520 & $(-0.624$ to -0.417$)$ \\
\hline HL at 2020 & 0.104 & $(0.048$ to 0.161$)$ & 0.136 & $(0.063$ to 0.210$)$ & 0.076 & $(-0.011$ to 0.162$)$ \\
\hline (constant) & 22.389 & (17.543 to 27.234$)$ & 18.601 & (12.791 to 24.412$)$ & 19.260 & (12.885 to 25.634$)$ \\
\hline Adjusted R-squared & 0.208 & & 0.210 & & 0.194 & \\
\hline
\end{tabular}

Multiple linear regression analysis was used. Significant differences are printed in bold $(p<0.05)$

maintain physical fitness [29]. Our findings indicate that higher HL before the pandemic might have protected against a decline in HRQOL after controlling for sociodemographic variables such as age, gender, and income. $\mathrm{HL}$ is personal knowledge and competencies that accumulate through daily activities, social interactions, and across generations [47]. Thus, HL is likely to be improved by education unlike other sociodemographic factors such as gender and economic status. Educational interventions at ordinary times to enable people to develop transferable skills in accessing, understanding, analyzing, and applying health information may be important to reduce health disparities during times of health risk.

This study had several limitations. First, the participants were recruited from the database of a survey research company; therefore, we were unable to include individuals uninterested in participating in such commercial surveys. However, the database made possible a longitudinal survey with comparatively few dropouts (5.7\% between 2020 and 2021). Second, the sample may not be representative of the general population of Japan. The proportion of university graduates in the sample was approximately $40 \%$, compared with $25 \%$ based on the 2017 Employment Status Survey by the Statistics Bureau of Japan. The generalizability of our findings should be carefully considered based on these characteristics. Third, self-administration of questionnaires requires at least a basic level of literacy, which may have biased the findings to some degree. Fourth, HL was measured using a self-report questionnaire. The responses represented the participants' own perceptions and may have been different from the objective ability. Fifth, we did not know whether there were participants who had become infected with COVID-19, quarantined, or had close contact with infected persons. A previous study reported lower HRQOL among people with COVID-19 symptoms [32]. Also, health-related behaviors and mental health issues can affect HRQOL, but this was not examined in this study. Further studies taking account of these factors are needed to better understand the association between HL and HRQOL.

\section{Conclusions}

In conclusion, the physical and mental dimensions of HRQOL and general HL declined significantly from immediately before the COVID-19 outbreak to 1 year later. The decline in HRQOL was more significant in those with lower economic status and a disease currently being treated, as well as among women, particularly for the mental dimension. Healthcare support for these vulnerable groups is crucial during and after the pandemic. Higher general HL before the COVID-19 outbreak was associated with a lesser decline in HRQOL. General HL may be important for attenuating the decline in HRQOL by promoting effective use of health information and adaptive behaviors toward health threats. Further studies are needed to better understand the association between HL and HRQOL.

\section{Abbreviations}

HL: Health literacy; HRQOL: Health-related quality of life

\section{Acknowledgements}

Not applicable.

\section{Authors' contributions}

$\mathrm{HI}$ conceptualized the study, conducted analyses, and wrote the manuscript. MK and TK provided input on the research idea and statistical analyses and edited the manuscript. All authors have reviewed and approved of the final manuscript.

\section{Funding}

This research was supported by JSPS KAKENHI [grant number 20H03919].

\section{Availability of data and materials}

The datasets used and/or analysed during the current study are available from the corresponding author on reasonable request. 


\section{Declarations}

\section{Ethics approval and consent to participate}

This study was approved by the Ethics Review Committee of Teikyo University (approval no. 20-227). All methods were performed in accordance with the Declaration of Helsinki. Prior to data collection, participants were given a copy of the participant information sheet and subsequently provided written informed consent.

\section{Consent for publication}

Not applicable.

\section{Competing interests}

The authors declare that they have no competing interests.

\section{Author details}

'Graduate School of Public Health, Teikyo University, 2-11-1 Kaga, Itabashi-ku, Tokyo 173-8605, Japan. ${ }^{2}$ Department of Health Communication, Graduate School of Medicine, The University of Tokyo, 7-3-1 Hongo, Bunkyo-ku, Tokyo 113-8655, Japan

\section{Received: 21 June 2021 Accepted: 25 October 2021}

\section{Published online: 27 November 2021}

\section{References}

1. Bell D, Blanchflower D. US and UK labour markets before and during the COVID-19 crash. Natl Inst Econ Rev. 2020;252:R52-69. https://doi.org/10.10 7/nie.2020.14

2. Breslau J, Finucane ML, Locker AR, Baird MD, Roth EA, Collins RL. A longitudinal study of psychological distress in the United States before and during the COVID-19 pandemic. Prev Med. 2021;143:106362. https://doi. org/10.1016/j.ypmed.2020.106362.

3. Di Gessa G, Price D. Changes in health and social well-being in the COVID19 clinically vulnerable older English population during the pandemic. J Epidemiol Community Health. 2021;75(11):1070-7. https://doi.org/10.1136/ jech-2021-216405.

4. Daly M, Sutin AR, Robinson E. Depression reported by US adults in 2017 2018 and March and April 2020. J Affect Disord. 2021;278:131-5. https://doi. org/10.1016/j.jad.2020.09.065.

5. Daly M, Sutin AR, Robinson E. Longitudinal changes in mental health and the COVID-19 pandemic: evidence from the UK household longitudinal study. Psychol Med. 2020:1-10. https://doi.org/10.1017/S0033291720004432.

6. Ettman CK, Abdalla SM, Cohen GH, Sampson L, Vivier PM, Galea S. Prevalence of depression symptoms in US adults before and during the COVID-19 pandemic. JAMA Netw Open. 2020;3(9):e2019686. https://doi. org/10.1001/jamanetworkopen.2020.19686.

7. Niedzwiedz CL, Green MJ, Benzeval M, Campbell D, Craig P, Demou E, et al. Mental health and health behaviours before and during the initial phase of the COVID-19 lockdown: longitudinal analyses of the UK household longitudinal study. J Epidemiol Community Health. 2021;75(3):224-31. https://doi.org/10.1136/jech-2020-215060.

8. McGinty EE, Presskreischer R, Han H, Barry CL. Psychological distress and loneliness reported by US adults in 2018 and April 2020. JAMA. 2020;324(1): 93-4. https://doi.org/10.1001/jama.2020.9740.

9. O'Kane SM, Lahart IM, Gallagher AM, Carlin A, Faulkner M, Jago R, et al. Changes in physical activity, sleep, mental health, and social media use during COVID-19 lockdown among adolescent girls: a mixed-methods study. J Phys Act Health. 2021;18(6):1-9. https://doi.org/10.1123/jpah.20200649.

10. Koinig KA, Arnold C, Lehmann J, Giesinger J, Köck S, Willenbacher W, et al. The cancer patient's perspective of COVID-19-induced distress-a crosssectional study and a longitudinal comparison of HRQOL assessed before and during the pandemic. Cancer Med. 2021;10(12):3928-37. https://doi. org/10.1002/cam4.3950.

11. Aihara $Y$, Kiyoshi M. Depressive symptoms in community-dwelling older adults in Japan before and during the COVID-19 pandemic. Int J Geriatr Psychiatry. 2021;36(7):1122-3. https://doi.org/10.1002/gps.5558.

12. Makizako H, Akaida S, Shono S, Shiiba R, Taniguchi $Y$, Shiratsuchi D, et al. Physical activity and perceived physical fitness during the COVID-19 epidemic: a population of 40- to 69-year-olds in Japan. Int J Environ Res Public Health. 2021;18(9). https://doi.org/10.3390/ijerph18094832.
13. Obuchi SP, Kawai H, Ejiri M, Ito K, Murakawa K. Change in outdoor walking behavior during the coronavirus disease pandemic in Japan: a longitudinal study. Gait Posture. 2021;88:42-6. https://doi.org/10.1016/j.gaitpost.2021.05. 005 .

14. Puccinelli PJ, da Costa TS, Seffrin A, de Lira CAB, Vancini RL, Nikolaidis PT, et al. Reduced level of physical activity during COVID-19 pandemic is associated with depression and anxiety levels: an internet-based survey. BMC Public Health. 2021;21(1):425. https://doi.org/10.1186/s12889-021-10470-z.

15. Paakkari L, Okan O. COVID-19: health literacy is an underestimated problem. Lancet Public Health. 2020;5(5):e249-50. https://doi.org/10.1016/S2468-2 667(20)30086-4

16. Abel T, McQueen D. Critical health literacy in pandemics: the special case of COVID-19. Health Promot Int. 2020;35(6):1612-3. https://doi.org/10.1093/hea pro/daaa040.

17. Corvo E, De Caro W. The paradox of the link between health literacy and health promotion: the case of COVID-19. Prof Inferm. 2020;73(3):219-22. https://doi.org/10.7429/pi.2020.733219.

18. Košir U, Sørensen K. COVID-19: the key to flattening the curve is health literacy. Perspect Public Health. 2020;1757913920936717:175791392093671. https://doi.org/10.1177/1757913920936717.

19. Cangussú LR, Barros IRP, Botelho Filho CAL, Sampaio Filho JDR, Lopes MR COVID-19 and health literacy: the yell of a silent epidemic amidst the pandemic. Rev Assoc Med Bras (1992). 2020;66(Suppl 2):31-3.

20. Hashemi-Shahri SM, Khammarnia M, Ansari-Moghaddam A, Setoodehzadeh F, Okati-Aliabad $H$, Peyvand M. Sources of news as a necessity for improving community health literacy about COVID-19. Med J Islam Repub Iran. 2020; 34:63. https://doi.org/10.47176/mjiri.34.63.

21. Spring H. Health literacy and COVID-19. Health Inf Libr J. 2020;37(3):171-2. https://doi.org/10.1111/hir.12322.

22. Van den Broucke $S$. Why health promotion matters to the COVID-19 pandemic, and vice versa. Health Promot Int. 2020;35(2):181-6. https://doi. org/10.1093/heapro/daaa042.

23. Sorensen K, Van den Broucke S, Fullam J, Doyle G, Pelikan J, Slonska Z, et al. Health literacy and public health: a systematic review and integration of definitions and models. BMC Public Health. 2012;12(1):80. https://doi.org/1 0.1186/1471-2458-12-80

24. Matterne U, Egger N, Tempes J, Tischer C, Lander J, Dierks ML, et al. Health literacy in the general population in the context of epidemic or pandemic coronavirus outbreak situations: rapid scoping review. Patient Educ Couns. 2021;104(2):223-34. https://doi.org/10.1016/j.pec.2020.10.012.

25. Okan O, Bollweg TM, Berens EM, Hurrelmann K, Bauer U, Schaeffer D. Coronavirus-related health literacy: a cross-sectional study in adults during the COVID-19 infodemic in Germany. Int J Environ Res Public Health. 2020; 17(15). https://doi.org/10.3390/ijerph17155503.

26. Niu Z, Qin Z, Hu P, Wang T. Health beliefs, trust in media sources, health literacy, and preventive behaviors among high-risk Chinese for COVID-19. Health Commun. 2021:1-9. https://doi.org/10.1080/10410236.2021.1880684.

27. Gautam V, S D, Rustagi N, Mittal A, Patel M, Shafi S, et al. Health literacy, preventive COVID 19 behaviour and adherence to chronic disease treatment during lockdown among patients registered at primary health facility in urban Jodhpur, Rajasthan. Diabetes Metab Syndr. 2020;15(1):20511. https://doi.org/10.1016/j.dsx.2020.12.023.

28. McCaffery KJ, Dodd RH, Cvejic E, Ayrek J, Batcup C, Isautier JM, et al. Health literacy and disparities in COVID-19-related knowledge, attitudes, beliefs and behaviours in Australia. Public Health Res Pract. 2020;30(4). https://doi.org/1 $0.17061 /$ phrp30342012.

29. Shiratsuchi D, Makizako H, Nakai $Y$, Taniguchi $Y$, Akanuma T, Yokoyama $K$, et al. Association of health literacy with the implementation of exercise during the declaration of COVID-19 state of emergency among Japanese community-dwelling old-old adults. Int J Environ Res Public Health. 2021; 18(4). https://doi.org/10.3390/ijerph18042100.

30. Tran TV, Nguyen HC, Pham LV, Nguyen MH, Nguyen HC, Ha TH, et al. Impacts and interactions of COVID-19 response involvement, health-related behaviours, health literacy on anxiety, depression and health-related quality of life among healthcare workers: a cross-sectional study. BMJ Open. 2020; 10(12):e041394. https://doi.org/10.1136/bmjopen-2020-041394.

31. Vu DN, Phan DT, Nguyen HC, Le LTH, Nguyen HC, Ha TH, et al. Impacts of digital healthy diet literacy and healthy eating behavior on fear of COVID19 , changes in mental health, and health-related quality of life among frontline health care workers. Nutrients. 2021;13(8):2656. https://doi.org/10.3390/ nu13082656. 
32. Nguyen HC, Nguyen MH, Do BN, Tran CQ, Nguyen TTP, Pham KM, et al. People with suspected COVID-19 symptoms were more likely depressed and had lower health-related quality of life: the potential benefit of health literacy. J Clin Med. 2020;9(4):965. https://doi.org/10.3390/jcm9040965.

33. Nguyen MH, Pham TTM, Nguyen KT, Nguyen YH, Tran TV, Do BN, et al. Negative impact of fear of COVID-19 on health-related quality of life was modified by health literacy, eHealth literacy, and digital healthy diet literacy: a multi-hospital survey. Int J Environ Res Public Health. 2021;18(9):4929. https://doi.org/10.3390/ijerph18094929.

34. Goto E, Ishikawa H, Nakayama K, Kiuchi T. Comprehensive health literacy and health-related behaviors within a general Japanese population: differences by health domains. Asia Pac J Public Health. 2018;30(8):717-26. https://doi.org/10.1177/1010539518806806.

35. Goto E, Ishikawa H, Okuhara T, Kiuchi T. Relationship of health literacy with utilization of health-care services in a general Japanese population. Prev Med Rep. 2019;14:100811. https://doi.org/10.1016/j.pmedr.2019.01.015.

36. Fukuhara S, Suzukamo Y. Manual of the SF-8 Japanese version. Kyoto: Institute for Health Outcomes and Process Evaluation Research; 2004.

37. Sorensen K, Van den Broucke S, Pelikan JM, Fullam J, Doyle G, Slonska Z, et al. Measuring health literacy in populations: illuminating the design and development process of the European Health Literacy Survey Questionnaire (HLS-EU-Q). BMC Public Health. 2013;13(1):948. https://doi.org/10.1186/14 71-2458-13-948

38. Nakayama K, Osaka W, Togari T, Ishikawa H, Yonekura Y, Sekido A, et al. Comprehensive health literacy in Japan is lower than in Europe: a validated Japanese-language assessment of health literacy. BMC Public Health. 2015; 15(1):505. https://doi.org/10.1186/s12889-015-1835-x.

39. Duong TV, Aringazina A, Baisunova G, Nurjanah, Pham TV, Pham KM, et al. Measuring health literacy in Asia: validation of the HLS-EU-Q47 survey tool in six Asian countries. J Epidemiol. 2017;27(2):80-6. https://doi.org/10.1016/j. je.2016.09.005.

40. Sorensen K, Pelikan JM, Rothlin F, Ganahl K, Slonska Z, Doyle G, et al. Health literacy in Europe: comparative results of the European health literacy survey (HLS-EU). Eur J Pub Health. 2015;25(6):1053-8. https://doi.org/10.1 093/eurpub/ckv043.

41. Antonelli-Salgado T, Monteiro GMC, Marcon G, Roza TH, Zimerman A, Hoffmann MS, et al. Loneliness, but not social distancing, is associated with the incidence of suicidal ideation during the COVID-19 outbreak: a longitudinal study. J Affect Disord. 2021;290:52-60. https://doi.org/10.1016/j. jad.2021.04.044.

42. Ueda M, Nordström R, Matsubayashi T. Suicide and mental health during the COVID-19 pandemic in Japan. J Public Health (Oxf). 2021. https://doi. org/10.1093/pubmed/fdab113.

43. Takahashi K. Job separation and reemployment amid the COVID-19 crisis in Japan. Japan Labor Issues. 2021;5(31):2-10.

44. Yanfei Z. How women bear the brunt of COVID-19's damages on work (continued, part II): catch up with men on the employment recovery. Japan Labor Issues. 2021;5(31):11-9.

45. Chudasama W, Gillies CL, Zaccardi F, Coles B, Davies MJ, Seidu S, et al. Impact of COVID-19 on routine care for chronic diseases: a global survey of views from healthcare professionals. Diabetes Metab Syndr. 2020;14(5):9657. https://doi.org/10.1016/j.dsx.2020.06.042.

46. Takakubo T, Odagiri Y, Machida M, Takamiya T, Fukushima N, Kikuchi H, et al. Changes in the medical treatment status of Japanese outpatients during the coronavirus disease 2019 pandemic. J Gen Fam Med. 2021;22(5): 246-61. https://doi.org/10.1002/jgf2.432.

47. Nutbeam D, Muscat DM. Health promotion glossary 2021. Health Promot Int. 2021. https://doi.org/10.1093/heapro/daaa157.

48. Gerich J, Moosbrugger R. Subjective estimation of health literacy-what is measured by the HLS-EU scale and how is it linked to empowerment? Health Commun. 2018;33(3):254-63. https://doi.org/10.1080/10410236.201 6.1255846

49. Zarocostas J. How to fight an infodemic. Lancet. 2020;395(10225):676. https://doi.org/10.1016/S0140-6736(20)30461-X.

50. Szmuda T, Ozdemir C, Ali S, Singh A, Syed MT, Sloniewski P. Readability of online patient education material for the novel coronavirus disease (COVID19): a cross-sectional health literacy study. Public Health. 2020;185:21-5. https://doi.org/10.1016/.jpuhe.2020.05.041

51. Valizadeh-Haghi S, Khazaal Y, Rahmatizadeh S. Health websites on COVID19: are they readable and credible enough to help public self-care? J Med Libr Assoc. 2021;109(1):75-83. https://doi.org/10.5195/jmla.2021.1020.

\section{Publisher's Note}

Springer Nature remains neutral with regard to jurisdictional claims in published maps and institutional affiliations.

\section{Ready to submit your research? Choose BMC and benefit from:}

- fast, convenient online submission

- thorough peer review by experienced researchers in your field

- rapid publication on acceptance

- support for research data, including large and complex data types

- gold Open Access which fosters wider collaboration and increased citations

- maximum visibility for your research: over $100 \mathrm{M}$ website views per year

At BMC, research is always in progress.

Learn more biomedcentral.com/submissions 